\title{
Effect of Eritoran, an Antagonist of MD2-TLR4, on Mortality in Patients With Severe Sepsis The ACCESS Randomized Trial
}

\begin{tabular}{l}
\hline Steven M. Opal, MD \\
\hline Pierre-Francois Laterre, MD \\
\hline Bruno Francois, MD \\
\hline Steven P. LaRosa, MD \\
\hline Derek C. Angus, MD, MPH \\
\hline Jean-Paul Mira, MD, PhD \\
\hline Xavier Wittebole, MD \\
\hline Thierry Dugernier, MD \\
\hline Dominique Perrotin, MD \\
\hline Mark Tidswell, MD \\
\hline Luis Jauregui, MD \\
\hline Kenneth Krell, MD \\
\hline Jan Pachl, MD \\
\hline Takeshi Takahashi, MD \\
\hline Claus Peckelsen, MD \\
\hline Edward Cordasco, DO \\
\hline Chia-Sheng Chang, MD \\
\hline Sandra Oeyen, MD \\
\hline Naoki Aikawa, MD, PhD \\
\hline Tatsuya Maruyama, MD, PhD \\
\hline Roland Schein, MD \\
\hline Andre C. Kalil, MD, MPH \\
\hline Marc Van Nuffelen, MD \\
\hline Melvyn Lynn, PhD \\
\hline Daniel P. Rossignol, PhD \\
\hline Jogadish Gogate, PhD \\
\hline Mary B. Roberts, MS \\
\hline Janice L. Wheeler, BS, RN \\
\hline Jean-Louis Vincent, MD, PhD \\
\hline for the ACCESS Study Group \\
\hline
\end{tabular}

1154 JAMA, March 20, 2013-Vol 309, No. 11 Corrected on March 19, 2013

Importance Eritoran is a synthetic lipid A antagonist that blocks lipopolysaccharide (LPS) from binding at the cell surface MD2-TLR4 receptor. LPS is a major component of the outer membrane of gram-negative bacteria and is a potent activator of the acute inflammatory response.

Objective To determine if eritoran, a TLR4 antagonist, would significantly reduce sepsis-induced mortality.

Design, Setting, and Participants We performed a randomized, double-blind, placebo-controlled, multinational phase 3 trial in 197 intensive care units. Patients were enrolled from June 2006 to September 2010 and final follow-up was completed in September 2011.

Interventions Patients with severe sepsis $(n=1961)$ were randomized and treated within 12 hours of onset of first organ dysfunction in a 2:1 ratio with a 6-day course of either eritoran tetrasodium (105 mg total) or placebo, with $n=1304$ and $n=657$ patients, respectively.

Main Outcome Measures The primary end point was 28-day all-cause mortality. The secondary end points were all-cause mortality at 3, 6, and 12 months after beginning treatment.

Results Baseline characteristics of the 2 study groups were similar. In the modified intent-to-treat analysis (randomized patients who received at least 1 dose) there was no significant difference in the primary end point of 28-day all-cause mortality with $28.1 \%(366 / 1304)$ in the eritoran group vs $26.9 \%(177 / 657)$ in the placebo group $(P=.59$; hazard ratio, $1.05 ; 95 \% \mathrm{Cl}, 0.88-1.26$; difference in mortality rate, $-1.1 ; 95 \%$ $\mathrm{Cl},-5.3$ to 3.1 ) or in the key secondary end point of 1-year all-cause mortality with $44.1 \%(290 / 657)$ in the eritoran group vs $43.3 \%(565 / 1304)$ in the placebo group, Kaplan-Meier analysis of time to death by 1 year, $P=.79$ (hazard ratio, 0.98; 0.851.13). No significant differences were observed in any of the prespecified subgroups. Adverse events, including secondary infection rates, did not differ between study groups.

Conclusions and Relevance Among patients with severe sepsis, the use of eritoran, compared with placebo, did not result in reduced 28-day mortality.

Trial Registration clinicaltrials.gov Identifier: NCT00334828

JAMA. 2013;309(11):1154-1162

www.jama.com

EVERE SEPSIS, A SYNDROME OF acute infection complicated by organ dysfunction, is caused by a dysregulated systemic inflammatory response. Sepsis can progress to systemic hypotension (septic shock),
Author Affiliations are listed at the end of this article.

Corresponding Author: Steven M. Opal, MD, Division of Infectious Diseases, Memorial Hospital of Rhode Island, 111 Brewster St, Pawtucket, RI 02860 (Steven_Opal@brown.edu)

Caring for the Critically III Patient Section Editor: Derek C. Angus, MD, MPH, Contributing Editor, JAMA (angusdc@upmc.edu). 
manifest by hypoperfusion of vital organs, multiple organ dysfunction, and death..$^{1-3}$

The Surviving Sepsis Campaign reported decreased mortality based on improved supportive care and evidencebased guidelines for diagnosis and timely intervention. ${ }^{4,5}$ However, mortality remains at approximately $30 \%^{4}$ and hospital admissions for severe sepsis have increased. ${ }^{3,5,6}$ Thus, improvements in care for severe sepsis remain a priority.

Lipopolysaccharide (LPS) or endotoxin, the major component of the outer membrane of gram-negative bacteria, is a potent stimulator of the inflammatory response. ${ }^{7}$ LPS triggers inflammation in gram-negative sepsis. Excessive amounts of gut-derived LPS released during intestinal hypoperfusion are implicated in sepsis caused by gram-positive and fungal infections. ${ }^{8,9}$

LPS signaling is initiated by activation of the MD2:toll-like receptor 4 (TLR4) on myeloid cells. ${ }^{7,10}$ Eritoran (E5564), a synthetic analog of lipid A and a potent and specific antagonist of LPS action, inhibits lipid A binding to MD2 and terminates MD2/TLR4mediated signaling invitro, exvivo, and invivo. ${ }^{11-13}$ In a phase 1 trial, eritoran blocked cytokine responses and clinical illness in healthy volunteers ${ }^{14}$ and in a phase 2 trial, eritoran-treated patients at high risk of death had lower mortality that was not statistically significant (eritoran $37.5 \%$ vs placebo $56.3 \%) .15$

The current trial evaluated the safety and efficacy of eritoran in reducing mortality in patients with severe sepsis.

\section{METHODS}

The ACCESS (a controlled comparison of eritoran and placebo in patients with severe sepsis) trial was designed as a randomized, double-blind, placebocontrolled, phase 3 clinical study. Enrollment occurred from June 2006 through September 2010 in 197 sites in North America, Europe, South America, Africa, Asia, and Australia. Predefined race and ethnicity information categories (white; black; Asian,
non-Japanese; Japanese; other; Hispanic, non-Hispanic) were noted at screening for planned subgroup analyses of efficacy and safety. Racial categories were self-reported and these differences were assessed to determine if TLR4 polymorphisms from different populations affected responsiveness to eritoran therapy.

\section{Patient Selection}

Patients who were at least 18 years old with early severe sepsis or septic shock and high risk of death were screened for participation. Severe sepsis was defined as documented evidence of bacterial or fungal infection, at least 3 criteria for systemic inflammatory response syndrome (SIRS eAppendix, available at http://www.jama.com), and at least 1 major organ dysfunction. Septic shock was defined as hypotension requiring vasopressors (eAppendix). High risk of death was defined as having an APACHE II (Acute Physiology and Chronic Health Evaluation) score of at least 21 and not greater than 37 . The onset of the first sepsis-related organ dysfunction had to occur less than 12 hours before administration of the study drug. Key exclusion criteria are listed in eAppendix.

\section{Randomization}

Eligible patients were assigned by centralized randomization using a computerized set of random numbers in a 2:1 eritoran:placebo ratio. Patients were assessed daily until hospital discharge or day 28 after randomization. Longterm follow-up evaluations occurred at 3,6 , and 12 months.

Critical care and infectious disease specialists at 3 clinical coordinating centers (United States, Belgium, and Japan) reviewed all screening data with study sites before enrollment to confirm that patients met all inclusion but no exclusion criteria. Approval from institutional review or ethics boards was obtained for all sites, and written informed consent was obtained from all patients or proxies as required by local authorities. A clinical evaluation committee (eAppendix) performed blinded evaluations of procedures throughout the study. The clinical evaluation committee determined the type, site, and causative organism of sepsis-defining infections.

\section{Study Procedures}

A total dose of $98.41 \mathrm{mg}$ eritoran (free acid) was administered. This amount is equal to the highest total dose of eritoran tetrasodium (105 $\mathrm{mg}$ ) used in the phase 2 severe sepsis study. ${ }^{15}$ Eritoran was administered intravenously as a loading dose of $26.24 \mathrm{mg}(6.56 \mathrm{mg} / \mathrm{h}$ for 4 hours), followed by a second loading dose of $13.12 \mathrm{mg}$ ( $6.56 \mathrm{mg} / \mathrm{h}$ for 2 hours) 12 hours later, and 9 maintenance doses of $6.56 \mathrm{mg}$ ( $3.28 \mathrm{mg} / \mathrm{h}$ for 2 hours) given every 12 hours thereafter. Matching placebo (vehicle) vials, with identical reconstitution and infusion instructions to the eritoran vials, were administered on the same schedule.

\section{Primary and Secondary Outcomes}

Survival was ascertained at 28 days after beginning treatment (the primary outcome measure) and at 3, 6, and 12 months through interviews with patients or surrogates. Serum samples of inflammatory markers were obtained at baseline, 30 minutes before the second loading dose, and on days 2 and 3. When not normally distributed, log-transformation of these data was performed for statistical analysis. Endotoxin activity assays were performed at baseline in a subset of patients by previously described methods (eAppendix). ${ }^{9}$

Eritoran efficacy was evaluated in prespecified patient subpopulations defined as follows: baseline APACHE II score groups (21-24, >24-26, >2631 , and $>31-37$ ); gram-negative vs gram-positive infections; infection sites (lung, abdomen, genitourinary, skin/ soft tissue, primary and catheterrelated bacteremia, central nervous system, and other); and baseline severity of illness by Sequential Organ Failure Assessment (SOFA) scores.

\section{Safety Measures}

Electrocardiograms, laboratory measurements, and physical examina-

JAMA, March 20, 2013-Vol 309, No. 111155 Corrected on March 19, 2013 
tions were performed throughout the active 28-day follow-up period or at hospital discharge. Adverse events were evaluated up to day 28 in all patients.
Infection-related adverse events were closely monitored to assess the potential host response attenuation risk by eritoran. ${ }^{15-17}$

Figure 1. Populations of Patients With Severe Sepsis Who Were Screened and Randomized to Receive Eritoran or Placebo

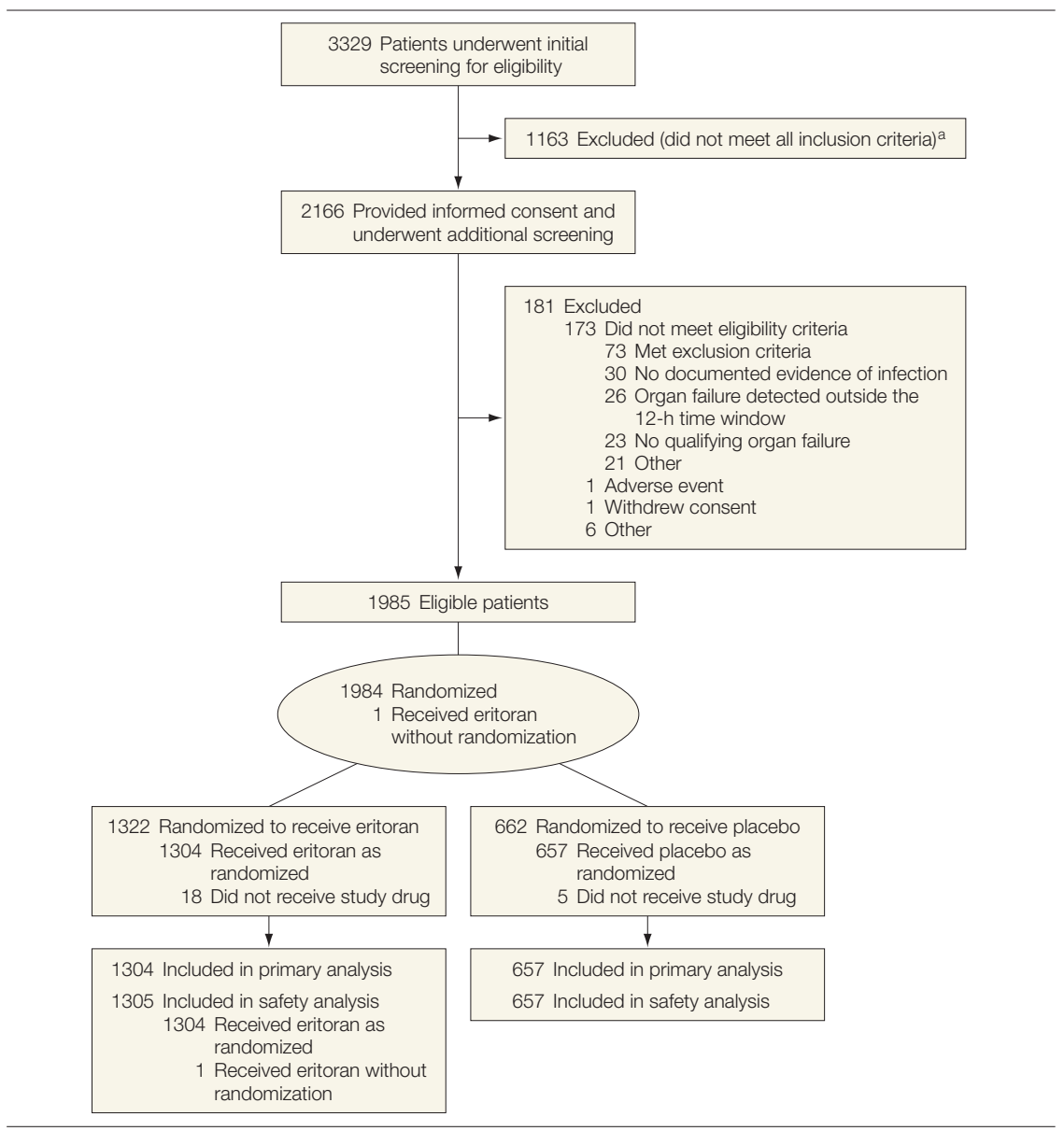

${ }^{a}$ Reasons for exclusion after initial screening are not available.

Table 1. Demographics of Patients With Severe Sepsis and High Risk of Death, MITT Population

\begin{tabular}{lcc}
\hline \multicolumn{2}{l}{} & \multicolumn{2}{c}{ No. (\%) } \\
\cline { 2 - 3 } & Eritoran $(\mathbf{n}=\mathbf{1 3 0 4})$ & Placebo $(\mathbf{n}=\mathbf{6 5 7})$ \\
\hline $\begin{array}{l}\text { Age, y } \\
\text { Mean (SD) }\end{array}$ & $65.4(15.0)$ & $65.8(15.1)$ \\
\hline Median (range) & $68(18-99)$ & $68(18-96)$ \\
\hline Men & $766(58.7)$ & $379(57.7)$ \\
\hline Women & $538(41.3)$ & $278(42.3)$ \\
\hline Race/ethnicity & $77(5.9)$ & $43(6.5)$ \\
Black & $1032(79.1)$ & $512(77.9)$ \\
\hline White & $73(5.6)$ & $30(4.6)$ \\
\hline Asian, non-Japanese & $83(6.4)$ & $19(2.1)$ \\
\hline Japanese & $39(3.0)$ & \\
\hline Other & & $19.9)$ \\
\hline
\end{tabular}

Abbreviations: MITT, modified intention to treat.

1156 JAMA, March 20, 2013-Vol 309, No. 11 Corrected on March 19, 2013

\section{Statistical Analysis}

A modified intent-to-treat (MITT) population, consisting of all randomized patients who received at least 1 dose of eritoran or placebo, was the primary population for analysis of eritoran efficacy. A per-protocol population was determined by the clinical evaluation committee's adjudication of study drug treatment compliance, eligibility criteria, and lack of major protocol deviations. The safety population consisted of all patients who received at least 1 dose of study drug and had at least 1 post-dose safety assessment. An independent data monitoring committee conducted interim efficacy and safety analyses. Statistical programming and analyses were performed using SAS version 9.1.3, service pack 4 .

The primary efficacy end point was evaluated by the difference in allcause 28-day mortality between the eritoran-treated and placebo-treated groups using a $\chi^{2}$ test. Kaplan-Meier estimates and log-rank statistics were used to assess survival time function throughout the 28 days and 1 year from treatment initiation. The outcome variable for a preplanned logistic regression analysis was all-cause 28-day mortality. Participants with unknown mortality status (who were lost to follow-up before day 28) were considered as dead. The logistic regression analysis with treatment and APACHE II score as fixed covariates was applied as a sensitivity analysis to support the primary analysis. The preplanned analysis of hazard ratio (HR) was unadjusted. HRs (eritoran vs placebo) and CIs were based on a Cox regression model with treatment group as a covariate.

All-cause mortality of $40 \%$ was predicted for the placebo group based on mortality rates in the phase 2 sepsis study for patient subgroups with APACHE II scores of 21 to $37 .{ }^{15} \mathrm{~A}$ sample size of 2000 patients was deemed sufficient to detect at least a $7.5 \%$ difference (estimated effect size based on the phase 2 trial results) in the 28-day mortality rate between eri- 
toran and placebo, with $90 \%$ power and an overall $\alpha$ level of .05 using a 2-sided $\chi^{2}$ test. Four interim analyses were planned and 1 additional safety interim analysis was conducted by the data monitoring committee. The nominal $\alpha$ levels assigned for the first 3 planned interim safety analyses and the additional interim safety analysis were $.0001, .0001, .0001$, and .0001 , respectively. The final planned interim analysis (considered as both efficacy and safety) is assigned an $\alpha$ value of .001 . Adjusted for 5 interim analyses, the $\alpha$ value assigned for the final analysis was .0498 using the interpolated boundary family.

\section{RESULTS}

\section{Study Population}

Written informed consent was obtained from 2166 patients, 1984 of whom were confirmed to be eligible by the clinical coordinating centers. These 1984 patients were randomized $(2: 1)$ to receive eritoran $(n=1322)$ or placebo $(n=662)$ (FIGURE 1). Enrollment began in June 2006 and was completed by Sepember 2010. Oneyear followup on all patients was completed by September 2011. Among randomized patients, 18 in the eritoran group and 5 in the placebo group did not receive treatment. Therefore, the MITT population comprised 1961 patients (eritoran, $\mathrm{n}=1304$; placebo, $\mathrm{n}=657$ ). One patient was treated with eritoran without randomization and became part of the safety population only (1962 patients: eritoran, $\mathrm{n}=1305$; placebo, $\mathrm{n}=657$ ). The vital status of the entire MITT population was determined at the 28-day follow-up time point.

The 2 study groups were well balanced with respect to demographic and baseline disease characteristics (Table 1, Table 2, and Table 3 ). The median APACHE II score was 26 in both groups. Septic shock was present in approximately $80 \%$ of patients at enrollment, and $65 \%$ of patients had at least 1 other organ dysfunction in addition to the initial organ dysfunction
Table 2. Baseline Disease Characteristics of Patients With Severe Sepsis and High Risk of Death, MITT Population

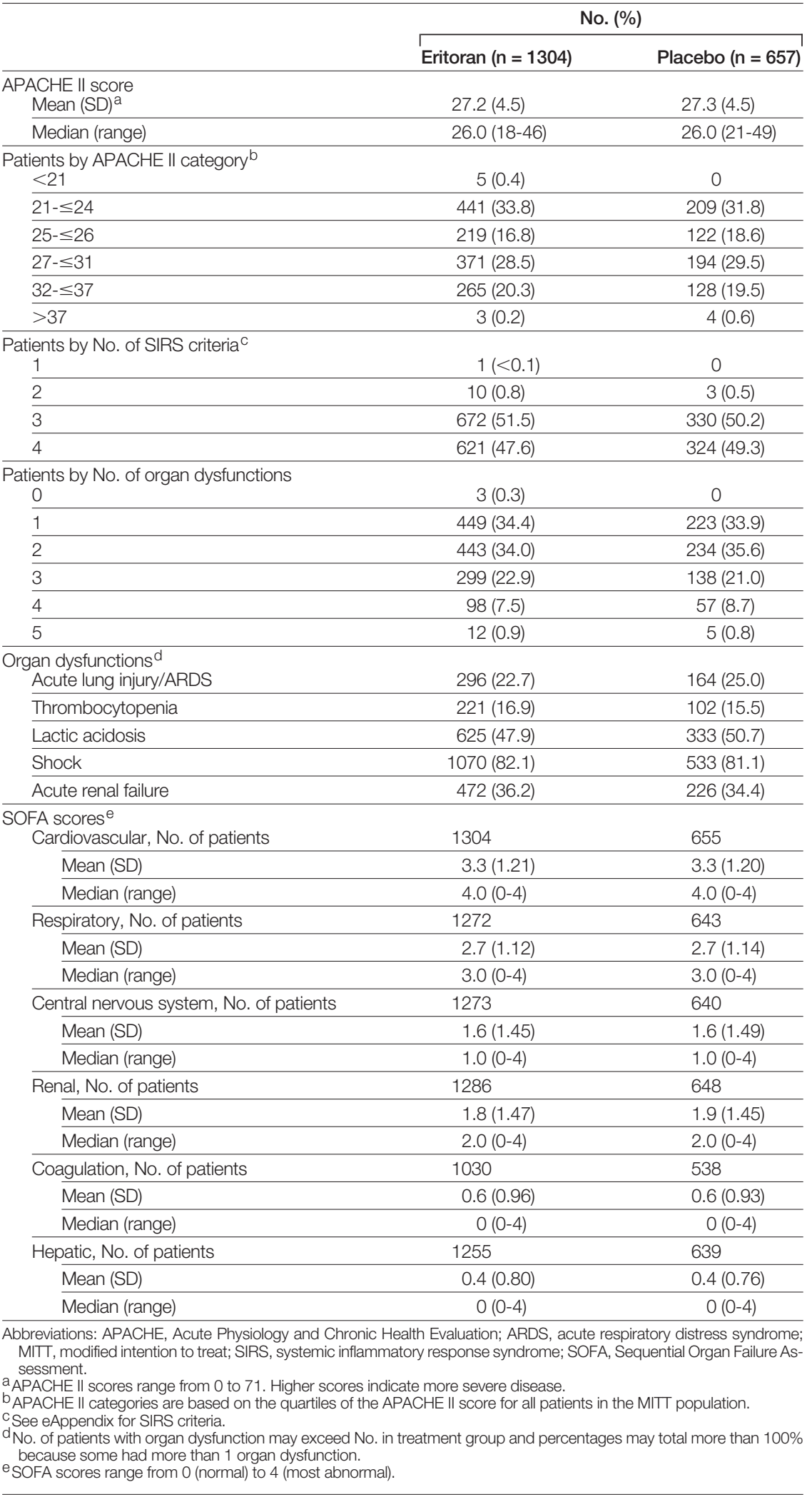


Table 3. Baseline Infection Characteristics of Patients With Severe Sepsis and High Risk of Death, MITT Population

\begin{tabular}{lcc}
\hline & \multicolumn{2}{c}{ No. (\%) } \\
\cline { 2 - 3 } & Eritoran $(\mathbf{n}=\mathbf{1 3 0 4 )}$ & Placebo $(\mathbf{n}=\mathbf{6 5 7})$ \\
\hline $\begin{array}{l}\text { Patients by type of infection } \\
\text { Gram-negative }\end{array}$ & $421(32.3)$ & $215(32.7)$ \\
\hline Gram-positive & $349(26.8)$ & $182(27.7)$ \\
\hline Mixed gram-negative and gram-positive & $136(10.4)$ & $76(11.6)$ \\
\hline Fungal & $19(1.5)$ & $4(0.6)$ \\
\hline Viral & $1(<0.1)$ & 0 \\
\hline Mixed bacterial/fungal/other & $34(2.6)$ & $15(3.3)$ \\
\hline Parasitic & 0 & $143(21.8)$ \\
\hline Unknown & $299(22.9)$ & $22(2.3)$ \\
\hline No evidence of infection & $45(3.5)$ & $329(50.1)$ \\
\hline Infection sites ${ }^{\text {a }}$ & $671(51.5)$ & $159(24.2)$ \\
\hline Lung & $305(23.4)$ & $149(22.7)$ \\
\hline Abdomen & $268(20.6)$ & $55(8.4)$ \\
\hline Genitourinary & $122(9.4)$ & $12(1.8)$ \\
\hline Skin/soft tissue & $38(2.9)$ & $11(1.7)$ \\
\hline Primary bloodstream & $35(2.7)$ & $14(2.1)$ \\
\hline Catheter-related bacteremia & $31(2.4)$ & $31(4.7)$ \\
\hline Central nervous system & $82(6.3)$ & \\
\hline Other
\end{tabular}

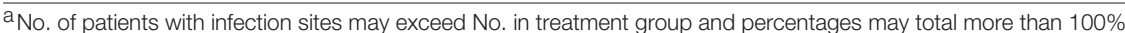
because some had more than 1 infection site.

required for enrollment. Gramnegative infections were documented in $35 \%$ of patients in both groups and gram-positive infections in $27 \%$. Mixed gram-negative/gram-positive infections occurred in $11 \%$ of patients. The most common causative organisms overall were Escherichia coli ( $22 \%$ of patients), Staphylococcus aureus (12\%), and Streptococcus pneumoniae (11\%). The lung was the infection site in approximately half of patients in each group. The overall incidence of bloodstream infection was $40 \%$ in the placebo group and $37.5 \%$ in the eritorantreated group. The per-protocol population, as adjudicated by the clinical evaluation committee, consisted of 1760 patients $(89.8 \%$ of the MITT population).

Comparable supportive care was administered during the 28-day study (TABLE 4). More than $90 \%$ of patients in both groups received some elements of early goal-directed sepsis therapy and $67 \%$ of patients received stress-dose systemic corticosteroids per protocol. Approximately $15 \%$ of patients received drotrecogin alfa (acti-

1158 JAMA, March 20, 2013-Vol 309, No. 11 Corrected on March 19, 2013 vated) therapy. Appropriate antimicrobial therapy and timely infection control was high in both treatment groups.

\section{Efficacy Assessments}

Treatment with eritoran did not significantly alter the primary study end point of 28-day mortality in the MITT population; $28.1 \%(366 / 1304)$ of patients in the eritoran group vs $26.9 \%$ (177/657) of patients in the placebo group. The vital status was unknown for 3 patients in each group $(P=.60)$. The difference in 28-day mortality between the eritoran and placebo groups was $-1.1 \%$ (95\% CI, $-5.3 \%$ to $3.1 \%$ ). The Kaplan-Meier survival analysis for the 28-day period showed no differences between the groups $(P=.58$ by log-rank test; [HR, 1.05; 95\% CI, 0.88 to 1.26]; FIGURE 2A). Similarly, KaplanMeier analysis of the key secondary end point, all-cause mortality at 1 year, showed no differences in outcome ( $P=.79$ by log-rank test; [HR, $0.98 ; 95 \%$ CI, 0.85 to 1.13 ]; Figure $2 \mathrm{~B}$ ).

Analysis of predefined subgroups, including patients at different APACHE II quartiles and baseline SOFA scores, those with septic shock (as defined by cardiovascular SOFA score $\geq 2$ ), those with gram-negative and gram-positive infections, and those with infection at different sites (including bloodstream infections or total confirmed infections), revealed no effect of eritoran on mortality vs placebo (FIGURE 3). A number of baseline variables were significantly associated with outcome including age, sex, race/ethnicity, number of organ dysfunctions, source of infection types, and primary focus of infection. A logistic regression model accounting for these variables failed to demonstrate a significant effect of treatment on outcome $(P=.93)$.

Levels of interleukin (IL)-1 $\beta$, IL-6, IL-8, IL-10, IL-12, tumor necrosis factor (TNF) $-\alpha$, and procalcitonin were elevated at baseline and decreased at subsequent time points. The changes were comparable for both groups (eTable 1). As anticipated, the cytokine data were not normally distributed. No significant differences were observed between groups by analyzing cytokine data with or without log-transformation.

The overall 28-day mortality rate in the subgroup of 209 patients for whom baseline endotoxin levels were measured was $18.4 \%$ for patients treated with eritoran and $29.4 \%$ for patients who received placebo, a result not consistent with the overall mortality rate in the study. A total of 85 patients (40.7\%; 52 in the eritoran group and 33 in the placebo group) had elevated baseline endotoxin activity assay (EAA) $(\geq .6)$. In these patients, eritoran treatment led to a 28-day mortality rate of $28.9 \%$ vs $27.3 \%$ in the placebo groups. In the subgroup of patients with EAA levels $<.6$, the mortality rate was $12 \%$ in the eritoran-treated group $(n=83)$ vs $31.7 \%$ in the placebo group $(n=41)$.

\section{Safety Assessments}

Eritoran was well tolerated with comparable numbers of treatmentemergent adverse events (TEAEs) and serious TEAEs between eritoran and placebo groups (eTable 2). TEAEs of special interest, including evidence of atrial fibrillation, hepatic dysfunction, 
renal dysfunction, hemorrhagic events, or phlebitis were similar in both groups. TEAEs related to infection were comparable for both groups (placebo group, 47\%; eritoran group, 46\%).

\section{COMMENT}

In this phase 3 trial of patients with severe sepsis, eritoran administration failed to demonstrate a significant effect, compared with placebo administration, on reducing all-cause 28-day mortality, 1-year mortality, or on any of the prespecified patient subgroups. These findings are in contrast with several preclinical studies and in phase 1 clinical trials in which eritoran terminated lipopolysaccharide (LPS)associated molecular and clinical events when administered in adequate doses. ${ }^{11-15}$ Despite these promising early results, no evidence of significant benefit was observed with eritoran in this large phase 3 trial.

Endotoxemia in the absence of an identifiable gram-negative infection is attributed to impaired mucosal barrier function with increased permeability of endotoxin and other pathogenassociated molecular patterns from the large reservoir of gram-negative bacteria in the gut. ${ }^{8,9,18,19}$ Variable and intermittent circulating LPS concentrations are often found at some point during most severe sepsis episodes and the endotoxemia level correlates with illness severity. ${ }^{8,9,18}$ Therefore, LPS has long been considered an attractive target for potential antisepsis therapies.

Previous therapeutic strategies targeted endotoxin with antibodies against the lipid A moiety of LPS, ${ }^{20,21}$ which failed in clinical trials and were later found to be weak binders and neutralizers of endotoxin in vitro. ${ }^{22}$ Other therapies aimed at reducing LPS levels, including bactericidal permeabilityincreasing protein, ${ }^{23}$ phospholipid emulsion, ${ }^{24}$ and polymixin B columns $^{25}$ also produced variable findings with inconsistent clinical trial results. Our results with the highly active LPS inhibitor eritoran in critically ill septic patients call into question the role of an endotoxin-blocking agent in halt- ing the inflammatory progression and organ dysfunction once sepsis is already underway.

There are multiple possible explanations for why eritoran did not improve treatment outcomes. First, the original hypothesis was predicated on the expectation that an LPS inhibitor would limit damage attributable to elevated serum endotoxin levels in patients with established severe sepsis.
The study design was intended to capture severely ill patients at high risk of endotoxemia in the early stages of progressive, sepsis-induced organ dysfunction. Based on previous observational studies, we predicted that the majority of patients enrolled would have elevated levels of circulating endotoxin. ${ }^{8,9}$ However, the study design did not use detectable endotoxemia as a precondition for enrollment and in the

Table 4. Summary of Background Care for Patients With Early Severe Sepsis and High Risk of Death During the 28-Day Study, MITT Population

\begin{tabular}{|c|c|c|}
\hline & \multicolumn{2}{|c|}{ No. (\%) } \\
\hline & $\begin{array}{l}\text { Eritoran } \\
(n=1304)\end{array}$ & $\begin{array}{l}\text { Placebo } \\
(\mathrm{n}=657)\end{array}$ \\
\hline \multicolumn{3}{|c|}{ Followed the early goal-directed therapy protocol } \\
\hline Yes & $1230(94.3)$ & $623(94.8)$ \\
\hline Fluid resuscitation & $1206(92.5)$ & $605(92.1)$ \\
\hline Vasopressors & $1123(86.1)$ & $567(86.3)$ \\
\hline Red cell transfusion & $378(29.0)$ & 190 (28.9) \\
\hline Central venous $\mathrm{O}_{2}$ monitoring & $372(28.5)$ & $204(31.1)$ \\
\hline Dobutamine & 242 (18.6) & $141(21.5)$ \\
\hline No & $74(5.7)$ & $34(5.2)$ \\
\hline \multicolumn{3}{|l|}{ Insulina } \\
\hline Yes & $930(71.3)$ & $467(71.1)$ \\
\hline No & $374(28.7)$ & $190(28.9)$ \\
\hline \multicolumn{3}{|l|}{ Drotrecogin alfa, activated ${ }^{b}$} \\
\hline Yes & $176(13.5)$ & $98(14.9)$ \\
\hline No & $1128(86.5)$ & $559(85.1)$ \\
\hline \multicolumn{3}{|l|}{ Low tidal volume protocols ${ }^{\mathrm{C}}$} \\
\hline Yes & $618(47.4)$ & $323(49.2)$ \\
\hline No & 498 (38.2) & 247 (37.6) \\
\hline Not applicable & $188(14.4)$ & $87(13.2)$ \\
\hline \multicolumn{3}{|l|}{ Baseline organ support } \\
\hline Vasopressor & $1132(86.8)$ & $576(87.7)$ \\
\hline Mechanical ventilation & $1024(78.5)$ & $535(81.4)$ \\
\hline Intensive care unit & $1289(98.8)$ & $654(99.5)$ \\
\hline \multicolumn{3}{|c|}{$\begin{array}{l}\text { Appropriate antimicrobial therapy as adjudicated } \\
\text { by CEC }\end{array}$} \\
\hline Yes & $1199(91.9)$ & $612(93.2)$ \\
\hline No & $59(4.5)$ & $23(3.5)$ \\
\hline Not applicable & $46(3.5)$ & $22(3.3)$ \\
\hline \multicolumn{3}{|c|}{$\begin{array}{l}\text { Adequate source control of infection as adjudicated } \\
\text { by CEC }\end{array}$} \\
\hline Yes & $454(34.8)$ & $238(36.2)$ \\
\hline No & $84(6.4)$ & $39(5.9)$ \\
\hline Not applicable & $766(58.7)$ & $380(57.8)$ \\
\hline \multicolumn{2}{|l|}{$\geq 1$ Concomitant medication ${ }^{d}$} & $446(67.9)$ \\
\hline Antibiotics & $1301(99.8)$ & $657(100.0$ \\
\hline \multicolumn{3}{|c|}{$\begin{array}{l}\text { Abbreviations: CEC, clinical evaluation committee; MITT, modified intention to treat. } \\
\text { a Insulin was administered to provide intensive glycemic control during the study. } \\
\text { b Drotrecogin alfa activated (brand name, Xigris). } \\
\text { C Low-tidal volume protocols were followed while patients received support from mechanical ventilation (ie, } 6 \mathrm{~mL} / \mathrm{kg} \text { ). } \\
\text { d Concomitant medications were ongoing from baseline or started after the first dose of study medication. } \\
\text { e Patients receiving a mean dose of more than } 0.5 \mathrm{mg} / \mathrm{kg} \text { prednisone (to a maximum of } 30 \mathrm{mg} / \mathrm{d} \text { ) or equivalent dose of } \\
\text { another agent in the } 7 \text { days prior to screening were excluded. Hydrocortisone at doses of at least } 300 \mathrm{mg} \text { per day for } \\
\text { treatment of septic shock was acceptable. }\end{array}$} \\
\hline
\end{tabular}


Figure 2. Kaplan-Meier Analysis of Time to Death by (A) Day 28 and (B) 1 Year in the MITT Population Who Received Eritoran or Placebo
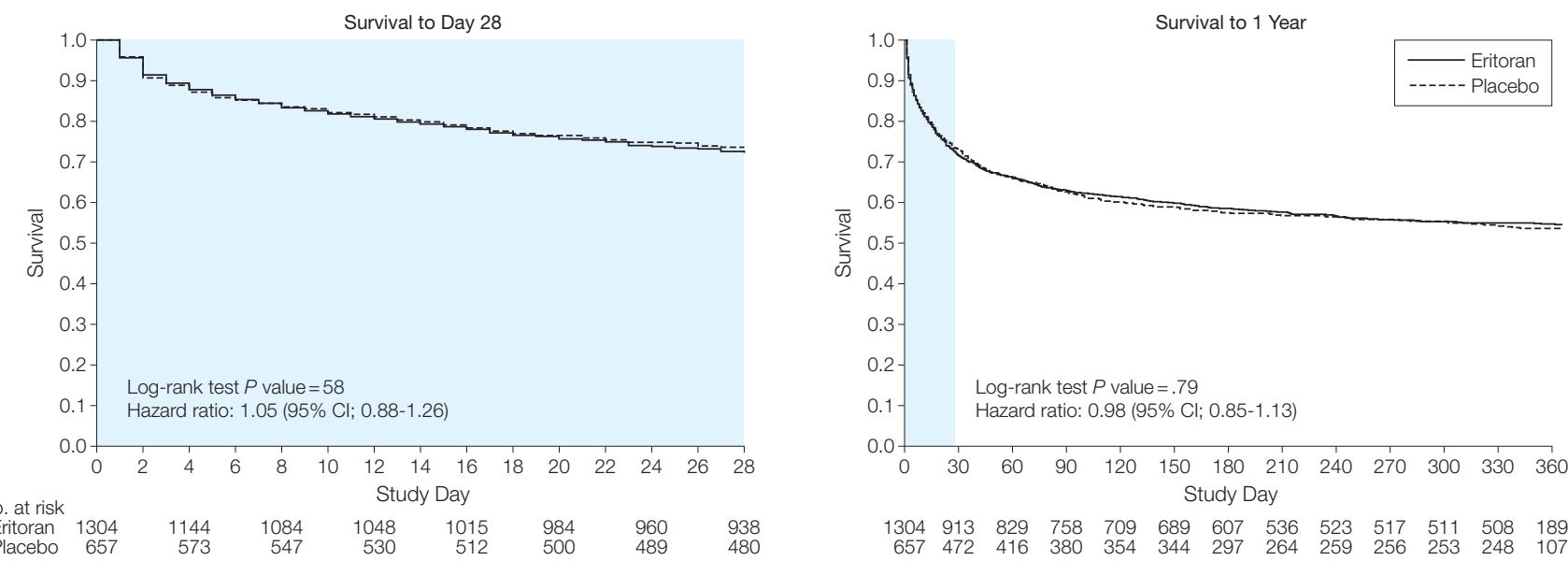

Patients who were alive past day 28 and at 1 year were censored at day 28 or at 1 year, respectively. Patients who did not die and were lost to follow-up within 28 days or 1 year were censored at their last contact date. Plot areas tinted blue indicate data for days 0 through 28.

Figure 3. Mortality (28-Day) in Subpopulations in the Modified Intention to Treat Population Who Received Eritoran or Placebo

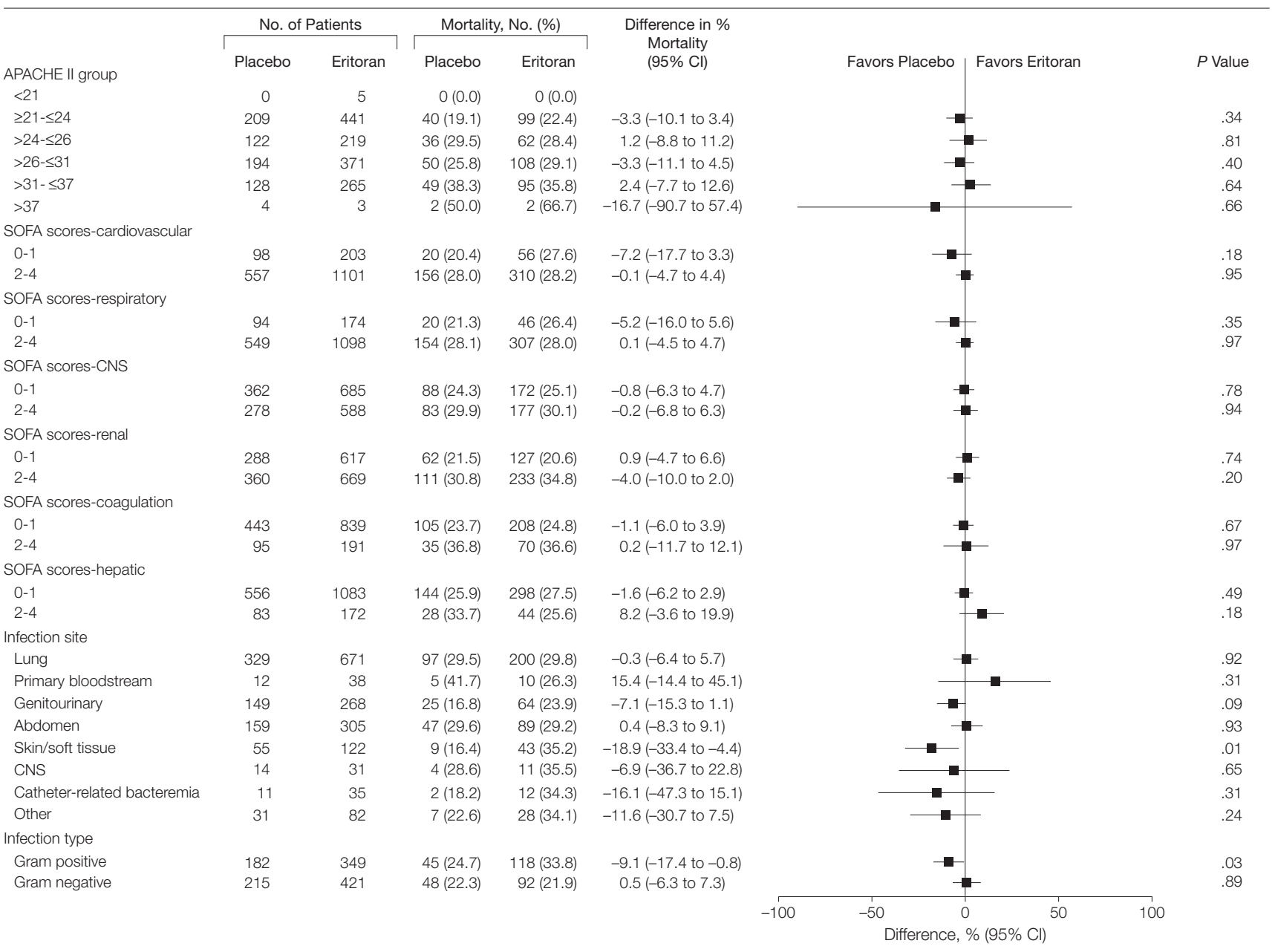

CNS indicates central nervous system.

1160 JAMA, March 20, 2013-Vol 309, No. 11

C2013 American Medical Association. All rights reserved. Corrected on March 19, 2013 
substudy of 209 patients who had baseline endotoxin levels measured by EAA, a surprisingly low percentage (41\%) had high endotoxin levels ( $\geq .6) .{ }^{9}$

Second, the observed mortality rate for patients who received placebo (27\%) was lower than the anticipated mortality rate $(40 \%)$ used in the original design. The low placebo event rate, which may indicate less severe disease in our patient population, would predict a lower response probability to eritoran. Consequently, this study might have been underpowered to detect a difference in outcome in this lower than expected mortality risk population. ${ }^{16}$

Third, improvements in patient care may also have contributed to a lower placebo event rate in this study than in previous trials. The APACHE 2 score as a predictor of intensive care unit mortality was validated more than 20 years ago and now consistently overestimates the mortality rate in sepsis patients. ${ }^{26}$ The majority of patients had aggressive fluid resuscitation as part of early goal-directed therapy and were treated in accordance with Surviving Sepsis Campaign guidelines. ${ }^{4}$ In addition, approximately $70 \%$ of patients received appropriate antimicrobial therapy within 4 hours of diagnosis, which probably improved survival. In patients with meningococcal sepsis, early administration of appropriate antibiotic therapy correlated with rapid clearance of endotoxin. ${ }^{27}$ A possible related factor was the delayed timing of eritoran administration, (ie, started a median of 9.15 hours after the onset of sepsis-induced organ dysfunction). This may not have been early enough to provide benefit for some endotoxemic patients with sepsis.

Fourth, in subgroup analyses, patients with gram-positive bacterial infections and those with skin and soft tissue infections appeared to do significantly worse in the eritoran-treated group than the placebo group. In the phase 2 trial, the subgroup of patients with gram-positive bacterial infections seemed to respond better to eritoran than those with gram-negative infections. ${ }^{15}$ The reasons for these differential outcomes between studies in gram-positive bacterial sepsis are unclear, but are most likely attributable to chance when analyzing differences between small subgroups. Future trials with this or other MD2-TLR4 inhibitors should proceed with caution if patients with gram-positive infections are included in the study population.

Many drugs commonly used in management of critically ill patients with sepsis can alter the host response to TLR4 signaling directly or indirectly, potentially limiting the benefits of this specific MD2:TLR4 inhibitor. Glucocorticoids, statins, catecholamines, macrolides, anesthetics, proton pump inhibitors, and other agents can modify the host inflammatory response and alter responsiveness to LPS inhibitors. ${ }^{28}$

Although LPS acts via TLR4 to activate NF-kappa-B and inflammatory gene transcription, other host-derived and microbial ligands are recognized by a number of pattern recognition receptors and can activate NF-kappa-Bdependent gene transcription independent of TLR4 signaling. ${ }^{7,29-31}$ Other common intermediary steps in the inflammatory cascade may be better targets for intervention.

In summary, in this phase 3 trial eritoran did not significantly improve outcome for patients with severe sepsis and septic shock. Eritoran joins a long list of other experimental sepsis treatments that do not improve outcomes in clinical trials in these critically ill patients.

Author Affiliations: Alpert Medical School of Brown University, Providence, Rhode Island (Dr Opal); St Luc University Hospital, UCL, Brussels, Belgium (Drs Laterre and Wittebole); Dupuytren University Hospital/ Inserm CIC 0801-CHU, Limoges, France (Dr Francois); Scott and White Healthcare, Texas A\&M Health Science Center College of Medicine, Temple, Texas (Dr LaRosa); University of Pittsburgh School of Medicine, Pittsburgh, Pennsylvania (Dr Angus); Université Paris Descartes, Sorbonne Paris Cité, Faculté de Médecine Cochin University Hospital, AP-HP, Paris, France (Dr Mira); St Pierre Hospital, Ottignies, Belgium (Dr Dugernier); CHU Bretonneau, University Francois Rabelais, Tours, France (Dr Perrotin); Baystate Medical Center, Springfield, Massachusetts (Dr Tidswell); Mercy Saint Vincent Medical Center, Toledo, Ohio (Dr Jaurequi); Eastern Idaho Regional Medical Center, Idaho Falls, Idaho (Dr Krell); Charles University, 3rd School of Medicine, Prague, Czech Republic (Dr Pachl); Vinohrady Teaching Hospital, Prague, Czech Republic (Dr Takahashi); Harlaching Hospital, Munich Municipal Hospital Group, Munich, Germany (Dr Peckelsen);
Remington-Davis, Inc, Columbus, Ohio (Dr Cordasco); China Medical University Hospital, Taiwan, Republic of China (Dr Chang); Ghent University Hospital, Ghent, Belgium (Dr Oeyen); Keio University School of Medicine, Tokyo, Japan (Drs Aikawa and Maruyama); University of Miami Miller School of Medicine, Miama Florida (Dr Schein); University of Nebraska Medical Center, Omaha (Dr Kalil); Eisai Inc, Woodcliff Lake, New Jersey (Drs Van Nuffelen, Lynn, Rossignol, Gogate, and Ms Wheeler); Brown University, Center for Primary Care and Prevention (Ms Roberts) and Division of Infectious Diseases (Dr Opal), Memorial Hospital of Rhode Island, Pawtucket (Ms Roberts); and Erasme University, Brussels, Belgium (Dr Vincent).

Author Contributions: Dr Opal had full access to all of the data in the study and takes responsibility for the integrity of the data and the accuracy of the data analysis. Study concept and design: LaRosa, Angus, Wittebole, Dugernier, Perrotin, Tidswell, Krell, Pachl, Takahashi, Chang, Aikawa, Schein, Lynn, Rossignol, Roberts, Wheeler, Vincent, Opal.

Acquisition of data: Laterre, LaRosa, Angus, Mira, Wittebole, Dugernier, Perrotin, Tidswell, Jauregui, Pachl, Peckelsen, Cordasco, Chang, Oeyen, Aikawa Maruyama, Schein, Nuffelen, Lynn, Roberts, Wheeler, Vincent, Opal.

Analysis and interpretation of data: Laterre, Françios, LaRosa, Angus, Mira, Wittebole, Dugernier, Perrotin, Tidswell, Jauregui, Pachl, Peckelsen, Chang, Oeyen, Aikawa, Maruyama, Schein, Kalil, Lynn, Rossignol, Gogate, Roberts, Vincent, Opal.

Drafting of the manuscript: Laterre, LaRosa, Angus, Wittebole, Dugernier, Perrotin, Tidswell, Krell, Pachl, Peckelsen, Chang, Schein, Kalil, Rossignol, Roberts, Opal.

Critical revision of the manuscript for important intellectual content: Laterre, Françios, LaRosa, Angus, Mira, Wittebole, Dugernier, Perrotin, Tidswell, Jauregui, Pachl, Takahashi, Peckelsen, Cordasco, Chang, Oeyen, Aikawa, Maruyama, Schein, Kalil, Nuffelen, Lynn, Rossignol, Gogate, Roberts, Wheeler, Vincent.

Statistical analysis: LaRosa, Angus, Wittebole, Perrotin Krell, Pachl, Chang, Schein, Lynn, Gogate, Roberts. Obtained funding: LaRosa, Angus, Wittebole, Perrotin Pachl, Schein, Lynn.

Administrative, technical, or material support: Laterre, LaRosa, Angus, Mira, Wittebole, Perrotin, Tidswell, Pachl, Takahashi, Peckelsen, Chang, Oeyen, Maruyama, Schein, Lynn, Rossignol, Roberts, Vincent. Study supervision: LaRosa, Angus, Mira, Wittebole Dugernier, Perrotin, Tidswell, Pachl, Cordasco, Aikawa, Maruyama, Schein, Kalil, Nuffelen, Lynn, Rossignol, Roberts, Opal.

Conflict of Interest Disclosures: All authors have completed and submitted the ICMJE Form for Disclosure of Potential Conflicts of Interest. Dr Opal reports receipt of grant/research support from Sirtris Pharmaceuticals; serving as a consultant to Kenta Biotech, Arsanis, Agennix, and Astra-Zeneca; and serving on the clinical coordinating center and the clinical evaluation committee in support of this study. Dr Laterre reports serving as a consultant to Eisai Inc for the protocol design, serving on the speaker's bureau of Eisai Inc for the ISICEM, and being a member of the clinical evaluation committee of the ACCESS study for Eisai Inc. Dr Francois reports serving as a consultant to LillyTalecris. Dr LaRosa reports receipt of grant/research support from Agennix AG and Astra-Zeneca; serving as a consultant to Talecris Biopharmaceuticals; Dr La Rosa reports receipt of a grant to the institution and receipt of fees for participation in review activities such as data monitoring boards, statistical analysis, and end point committees from Eisai Inc; and serving as a consultant for ExThera Medical. Dr Angus reports receipt of a grant to the institution, consulting fees, and travel support from Eisai Inc; receipt of consultancy 
fees from Roche Diagnostics, Medlmmune, Pfizer Inc, and Idaho Technologies; and serving on the data and safety monitoring board for Eli Lilly. Dr Mira reports serving as a consultant to Eisai Inc as a member of the clinical evaluation committee for the ACCESS study and as the national coordinator for France for this study. Dr Mira also reports serving as a consultant for Eli Lilly, Novartis, Astra-Zeneca, LFB Biotechnologies, and Merck. Dr Chang reports receipt of grant/research support from Eisai Inc. Dr Aikawa reports being a medical advisor for the eritoran phase 3 clinical trial sponsored by the Eisai Co. Dr Aikawa reports receipt of travel expenses from Eisai Inc. Dr Schein reports receipt of fees and travel support from Eisai Inc; receipt of fees for participation in review activities such as data monitoring boards, statistical analysis, and end point committees from Eisai Medical Research; and receipt of a grant to the institution form the University of Miami. r Kalil reports receipt of grant/research support from Eisai Inc. Dr Vincent reports receipt of grant/research support, serving as a consultant, and serving on the speaker's bureau for Eisai Inc.

Funding/Support: Eisai Inc, Woodcliff Lake, NJ, provided financial support for the initial design, study medications and conduct of the study.

Role of the Sponsor: The sponsor had no role in the final statistical analysis, interpretation of the data, preparation, review, or approval of the manuscript.

Disclaimer: Dr Angus, Contributing Editor for JAMA was not involved in the evaluation or decision to publish this article.

Online-Only Material: The eAppendix and eTables

1 and 2 are available at http://www.jama.com. Additional Contributions: We dedicate this report to the memory of Dr Alec E. Wittek, who served as study director until his untimely death just before the study conclusion. The authors would like to thank and acknowledge William Tillis, MD, of The University of IIlinois College of Medicine at Rockford, who contributed a large number of patients in this study. Dr Tillis reports no conflict of interest and received no compensation from Eisai Inc. or any other company other than for research study work. We also thank and acknowledge Mary Roberts, an independent academic statistician for Brown University, who performed all the primary and secondary end point analyses and the safety and support analyses. She received no financial support by Eisai or any other entity in performing these statistical analyses. We acknowledge The Medicine Group for editorial assistance in the development of this article.

\section{REFERENCES}

1. Angus DC, Linde-Zwirble WT, Lidicker J, Clermont G, Carcillo J, Pinsky MR. Epidemiology of severe sepsis in the United States: analysis of incidence, outcome, and associated costs of care. Crit Care Med. 2001;29(7):1303-1310.

2. Hotchkiss RS, Opal SM. Immunotherapy for sepsis-a new approach against an ancient foe. N Eng/ J Med. 2010;363(1):87-89.

3. Lagu T, Rothberg MB, Shieh MS, Pekow PS, Stingrub JS, Lindenauer PK. Hospitalizations, costs, and outcomes of severe sepsis in the United States 2003 to 2007 [published online September 29, 2011]. Crit Care Med. 2011. doi:10.1097/CCM ob013e318232db65.

4. Levy MM, Dellinger RP, Townsend SR, et al. The Surviving Sepsis Campaign: results of an international guideline-based performance improvement program targeting severe sepsis. Intensive Care Med. 2010;36(2):222-231

5. Kumar G, Kumar N, Taneja A, et al; Milwaukee Initiative in Critical Care Outcomes Research Group of Investigators. Nationwide trends of severe sepsis in the 21st century (2000-2007). Chest. 2011;140(5): $1223-1231$.

6. Dombrovskiy VY, Martin AA, Sunderram J, Paz HL. Rapid increase in hospitalization and mortality rates for severe sepsis in the United States: a trend analysis from 1993 to 2003. Crit Care Med. 2007;35(5): 1244-1250.

7. Beutler BA. TLRs and innate immunity. Blood. 2009; 113(7):1399-1407.

8. Opal SM, Scannon PJ, Vincent J-L, et al. Relationship between plasma levels of lipopolysaccharide (LPS) and LPS-binding protein in patients with severe sepsis and septic shock. J Infect Dis. 1999;180(5): 1584-1589.

9. Marshall JC, Foster D, Vincent J-L, et al; MEDIC study. Diagnostic and prognostic implications of endotoxemia in critical illness: results of the MEDIC study. J Infect Dis. 2004;190(3):527-534.

10. Shimazu R, Akashi S, Ogata H, et al. MD-2, a molecule that confers lipopolysaccharide responsiveness on Toll-like receptor 4. J Exp Med. 1999;189(11): 1777-1782.

11. Rossignol DP, Lynn M. Antagonism of in vivo and ex vivo response to endotoxin by E5564, a synthetic lipid A analogue. J Endotoxin Res. 2002;8(6):483488.

12. Mullarkey $M$, Rose JR, Bristol J, et al. Inhibition of endotoxin response by e5564, a novel toll-like receptor 4-directed endotoxin antagonist. J Pharmacol Exp Ther. 2003;304(3):1093-1102.

13. Rossignol DP, Wasan KM, Choo E, et al. Safety, pharmacokinetics, pharmacodynamics, and plasma lipoprotein distribution of eritoran (E5564) during continuous intravenous infusion into healthy volunteers. Antimicrob Agents Chemother. 2004;48(9):32333240

14. Lynn M, Rossignol DP, Wheeler JL, et al. Blocking of responses to endotoxin by E5564 in healthy volunteers with experimental endotoxemia. J Infect Dis. 2003;187(4):631-639

15. Tidswell M, Tillis W, Larosa SP, et al; Eritoran Sepsis Study Group. Phase 2 trial of eritoran tetrasodium (E5564), a toll-like receptor 4 antagonist, in patients with severe sepsis. Crit Care Med. 2010;38(1): 72-83.

16. Kalil AC, LaRosa SP, Gogate J, Lynn M, Opal SM; Eritoran Sepsis Study Group. Influence of severity of illness on the effects of eritoran tetrasodium (E5564) and on other therapies for severe sepsis. Shock. 2011; 36(4):327-331

17. Hawkins LD, Christ WJ, Rossignol DP. Inhibition of endotoxin response by synthetic TLR4 antagonists. Curr Top Med Chem. 2004;4(11):1147-1171.

18. Danner RL, Elin RJ, Hosseini JM, Wesley RA, Reilly $J M$, Parillo JE. Endotoxemia in human septic shock. Chest. 1991;99(1):169-175.

19. Hurley JC. Concordance of endotoxemia with gram-negative bacteremia in patients with gramnegative sepsis: a meta-analysis. J Clin Microbiol. 1994; 32(9):2120-2127.

20. Greenman RL, Schein RMH, Martin MA, et al; The XOMA Sepsis Study Group. A controlled clinical trial of E5 murine monoclonal IgM antibody to endotoxin in the treatment of gram-negative sepsis. JAMA. 1991; 266(8):1097-1102

21. Ziegler EJ, McCutchan JA, Fierer J, et al. Treatment of gram-negative bacteremia and shock with human antiserum to a mutant Escherichia coli. N Engl J Med. 1982;307(20):1225-1230

22. Warren HS, Amato SF, Fitting C, et al. Assess- ment of ability of murine and human anti-lipid A monoclonal antibodies to bind and neutralize lipopolysaccharide. J Exp Med. 1993;177(1):8997.

23. Levin M, Quint PA, Goldstein B, et al. Recombinant bactericidal/permeability-increasing protein $\left(\mathrm{rBP}_{21}\right)$ as adjunctive treatment for children with severe meningococcal sepsis: a randomised trial: rBPI21 Meningococcal Sepsis Study Group. Lancet. 2000 356(9234):961-967.

24. Dellinger RP, Tomayko JF, Angus DC, et al; Lipid Infusion and Patient Outcomes in Sepsis (LIPOS) Investigators. Efficacy and safety of a phospholipid emulsion (GR270773) in gram-negative severe sepsis: results of a phase II multicenter, randomized, placebo-controlled, dose-finding clinical trial. Crit Care Med. 2009;37(11):2929-2938.

25. Cruz DN, Antonelli M, Fumagalli $R$, et al. Early use of polymyxin $B$ hemoperfusion in abdominal septic shock: the EUPHAS randomized controlled trial. JAMA. 2009;301(23):2445-2452.

26. Vincent JL, Opal SM, Marshall JC. Ten reasons why we should not use severity scores as entry criteria for clinical trials or in our treatment decisions: the arguments against the use of APACHE II as entry criteria for sepsis studies. Crit Care Med. 2010;38 (1):283-287.

27. Brandtzaeg P, Kierulf P, Gaustad P, et al. Plasma endotoxin as a predictor of multiple organ failure and death in systemic meningococcal disease. J Infect Dis. 1989;159(2):195-204.

28. Wittebole $X$, Castanares-Zapatero D, Laterre PF. Toll-like receptor 4 modulation as a strategy to treat sepsis [published online April 14, 2010]. Mediators Inflamm. 2010;(396):568. doi:10.1155/2010/568396. 29. Figueiredo RT, Fernandez PL, Mourao-Sa DS, et al. Characterization of heme as activator of Toll-like receptor 4. J Biol Chem. 2007;282(28):20221-20229. 30. Malley R, Henneke P, Morse SC, et al. Recognition of pneumolysin by toll-like receptor 4 confers resistance to pneumococcal infection. Proc Natl Acad Sci U S A. 2003;100(4):1966-1971.

31. Chow JC, Young DW, Golenbock DT, Christ WJ, Gusovsky F. Toll-like receptor-4 mediates lipopolysaccharide-induced signal transduction. J Biol Chem. 1999;274(16):10689-10692. 